\title{
НАЗВАНИЯ ЧЛЕНОВ РУССКИХ ПОЛИТИЧЕСКИХ ПАРТИЙ И ИХ ОТРАЖЕНИЕ В ПОЛЬСКОЙ ПРЕССЕ
}

\author{
NAMES OF THE MEMBERS OF RUSSIAN POLITICAL PARTIES \\ AND THEIR REPRESENTATION IN THE POLISH PRESS
}

\author{
ИОЛАНТА ЮЗВЯК
}

\begin{abstract}
The aim of this paper is to present the word formation strategies that are used to create the names of the members of Russian political parties. In the second part of the article the author focuses on difficulties associated with introducing these names into the Polish press with regard to their cultural connotations.

Jolanta Jóźwiak, Uniwersytet Kazimierza Wielkiego, Bygdoszcz - Polska.
\end{abstract}

Язык средств массовой информации, в том числе прессы, постоянно обогащается словами, связанными с актуальными вопросами, привлекающими внимание общества в данный исторический момент. В период изменения власти, выборов, предвыборной борьбы, а также после выборов в прессе появляется довольно много слов, относящихся к политической жизни. Поскольку партии стараются быть замеченными на политической сцене, наименования лиц по партийной принадлежности выступают в прессе с особой активностью.

Предметом настоящего анализа являются названия членов русских политических партий и способы их отражения в польских публицистических текстах. Материал отобран из интернет-изданий русской и польской прессы.

В русском языке среди названий членов политических партий выделяются: наименования аналитического характера, суффиксальные образования, а также сложения в сочетании с суффиксацией.

Стилистически нейтральным по своему характеру способом введения в русский публицистический текст названий членов политических партий является аналитическая модель: член (партии) + наименование партии, ср. члены партии „Единая Россия”, члены ЛДПР, члены КПРФ, члены партии „Яблоко" и т.п.

Как известно, политические партии и тем самым члены этих партий, особенно во время напряженной политической борьбы, вызывают много эмоций, что рано или поздно тем или иным образом отражается 
в языке. Поэтому, кроме официальных, эмоционально нейтральных образований, в прессе широко распространены их разговорные синонимы. Некоторые из них употребляются наравне с официальными наименованиями, другие - только окказионально. Одни из них проявляют высокую частотность употребления, другие представлены только единичными примерами. Количество употреблений зависит, конечно, от позиции данной политической организации, количества ее сторонников и роли, которую в данный момент она играет на политической сцене.

Довольно часто встречаются однословные названия членов партий, мотивированные полными или сокращенными названиями политических партий. Исследуемые единицы образуются, например, путем суффиксации одного из компонентов аналитического наименования партии при одновременном эллипсисе остальных компонентов, ср. родиновиы (< Партия Родина), яблочники (< Российская демократическая партия „Яблоко" 1 ), или только путем эллипсиса одного из компонентов, ср. патриоты (< Патриоты России).

Стоит отметить, что название члена партии „Яблоко" употреблялось вначале в двух вариантах, один из которых не вошел в конечном итоге в русский язык в значении 'член партии'. Имеются в виду слова яблоковиы и яблочники. Слово яблоковиы редко появляется в контекстах, относящихся к политическим событиям, ср. „Яблоко Ростовской области - одно из самых активных региональных отделений, с которого берут пример и к которому приезжают за получением опыта яблоковиы из других регионов". Вероятно, именно потому, что данное образование употреблялось уже в области компьютерной лексики в совсем другом значений, т.е. 'работник компьютерной американской фирмы Apple', оно не было воспринято носителями языка удачным. В лексический состав вошло слово яблочники, ср.

Как стало известно „РГ”, в начале осени правые и „яблочники” действительно приложили реальные усилия, чтобы согласовать свои позиции и даже, по некоторым данным, состоялась личная встреча Григория Явлинского и Анатолия Чубайса.

Следующая группа анализируемых названий мотивируется атрибутивным компонентом составного наименования партии, явно ука-

\footnotetext{
1 Российская демократическая партия „Яблоко” - партия, название которой составлено из первых букв фамилий основавших ее лидеров: Явлинский, Болдырев, Лукин (ТССРЯ).

2 Ср.: „Тем не менее, яблоковиы, хоть и не монополисты, но держат крупный кусок рынка со своими ipod \& tunes”, а также „Яблоковиы изменили картинку, убрав значок bluetooth".
} 
зывающим на идеологическое направление данной организации, ср. аграрники и аграрии (< Аграрная партия России), либералы и либерал-демократы (< Либерально-демократическая партия России), коммунисты (< Коммунистическая партия Российской Федерации), правые (< Союз Правых Сил). Следует отметить, что упомянутые наименования употребляются не только в значении 'член партии', но также вместо полного наименования партии и для обозначения сторонника определенного идеологического направления. В большинстве случаев это зафиксировано в новейших словарях ${ }^{3}$, например, в Русском семантическом словаре под ред. Н.Ю. Шведовой ${ }^{4}$ (РСС) или в Толковом словаре современного русского языка под. ред. Г.Н. Скляревской ${ }^{5}$ (ТССРЯ).

Как было уже указано, единицы коммунисты, либералы, правые ассоциируются у носителей языка с определенной идеологией. Надо, однако, подчеркнуть, что у названия коммунисты коннотация шире, так как данное слово тесно связано с историей страны и с Советским Союзом как источником коммунистической идеологии. Можно полагать, что независимо от исторических обстоятельств и возможных изменений наименования партии, следующей данной идеологии, ее члены будут именоваться коммунистами. Относительно слов либералы и либерал-демократы можно сказать, что они действительно соотносятся с идео-

${ }^{3}$ Например, в Русском семантическом словаре под ред. Н.Ю. Шведовой (РСС) или в Толковом словаре современного русского языка под ред. Г.Н. Скляревской (ТССРЯ). Ср.: аграрий=аграрник ' 1 . Тот, кто занимается сельским хозяйством; землевладелец, 2. полит. член аграрной партии' (ТССРЯ); аграрии 'полит. мн. член аграрной партии; фракция в Государственной Думе, состоящая из представителей этой партии и их сторонников; представители этой партии и фракции' (ТССРЯ); коммунист '1. Член Коммунистической партии Российской Федерации (КПРФ) и коммунистических партий стран дальнего и ближнего зарубежья; последователь коммунистической идеи, 2. только мн. полит. Правительственная оппозиция; фракция Госдумы, состоящая из членов КПРФ и их сторонников' (ТССРЯ); либерал '1. Сторонник, последователь либерализма, идеологического и политического направления, объединяющего сторонников парламентского строя, демократических свобод и свободного предпринимательства, 2. Член либеральной партии' (РСС); либерал-демократы 'Либерально-демократическая партия России; представители этой партии' (ТССРЯ), правые 'полит. Общественные и политические группы и партии, придерживающиеся консервативных политических убеждений, взглядов и методов политической борьбы; представители этих групп и партий; против. левые' (ТССРЯ), правый “"Союз правых сил” (блок партий и движений правоцентристской ориентации, возглавляемый С. Кириенко, И. Хакамадой и Б. Немцовым; фракция представителей этого блока в Госдуме' (ТССРЯ).

4 Русский семантический словарь, под ред. Н.Ю. Шведовой, т. 1, Москва 1998.

5 Толковый словарь современного русского языка, под ред. Г.Н. Скляревской, Москва 2001. 
логией, прежде всего западной, особенно великобританской, где ее истоки.

Некоторые названия членов партии возникают в результате суффиксации буквенной аббревиатуры полного названия партии, ср.: СПСовиы рально-демократическая партия России), эСэРовиы (<СР - Справедливая Россия). В части образований отражается произношение аббревиатуры, например, элдэпээровиы (<ЛДПР), эспээсники или эспээсовиы (<СПС), ср.: „Если «эспээсовиы» потеряют новый город на следующих выборах, спасибо они могут сказать Чубайсу".

Особое внимание следует обратить на синонимичное названию эСэРовиы, широко употребляемое другое наименование членов партии "Справедливая Россия", а именно эСэРы/эсэры/эсеры (<СР). В русском языке раньше существовало слово эсер в значении 'социалист-революционер' (ТССРЯ). Вследствие этого у некоторых читателей, обладающих определенными знаниями, оно может вызывать дополнительные ассоциации относительно характера данной партии.

Среди русских номинаций рассматриваемого типа выделяются названия, образованные суффиксальным способом от фамилий лидеров политических партий или лиц, связанных с ними, ср. жириновец 'публ. 1. Сторонник В.В. Жириновского; член Либерально-демократической партии России, возглавляемой В.В. Жириновским. 2. только мн. Фракция Государственной Думы, состоящая из членов ЛДПР и их сторонников, возглавляемая В.В. Жириновским' (ТССРЯ); явлинцы 'публ. Сторонники Г. Явлинского из партии „Яблоко”' (ТССРЯ). К ним причисляются также не отмеченные в словарях аналогичные по семантике гайдаровиы, горбачевцы, путинцы, чубайсовиы/чубаевиы. В русских публицистических текстах среди названий членов партий, возникших от фамилий их лидеров, наибольшей частотностью употребления обладает слово жириновиы. И это не случайно. Лидер ЛДПР с начала создания этой партии являлся главным и наиболее выразительным лицом, о нем упоминалось в средствах массовой информации, политическая иерархия была строго определена и широко известна. Очевидно, что в основу образования названий членов данной организации могут лечь фамилии основателей и лидеров, отождествляемых с данной партией, ярко выделяющихся (не всегда положительно) на фоне других ее представителей. Отрицательные ассоциации вызывает фамилия лидера На-

6 В статье сохраняются оригинальные орфографические записи. Следует отметить, что названия членов партий с суффиксом -овеи, пишутся слитно или через дефис. Также другие названия появляются в печати в орфографических вариантах, например, со строчными или прописными буквами в середине слова. 
ционал-Большевистской Партии Эдуарда Лимонова, что привело к возникновению названия членов его партии - лимонщики.

Другие примеры, хотя их в официальной прессе немного, показывают, что соответствующие ассоциации могут передаваться находящимся в составе названия члена партии экспрессивным суффиксом, например: коммуняка 'разг. презрит. Коммунист, сторонник коммунистической идеологии' (ТССРЯ) и 'насмешл. неодобр. (бран.) разг.-сниж. О коммунисте, активисте коммунистической партии и Советской власти в бывшем СССР 7 (БСРРР).

Следующим способом образования названий членов партий является сложение с суффиксацией. Примером могут здесь служить слова: единороссовцы (< Единая Россия") и справедливороссы (< Справедливая Россия), ср.:

Эти средства „единороссовиы должны были заплатить за упомянутую публикацию, однако, как следует из заметок в некоторых СМИ, деньги эти остались в „копилке” партии „Единая Россия".

Вчера свершилось то, о чем давно говорили - нет, не большевики, а „сnраведıивороссы" и „элдэпээровиыь" (в кулуарах): зам Жириновского депутат Госдумы Алексей Митрофанов покинул ЛДПР, в которой состоял 16 лет, и перешел в „Справедливую Россию” Миронова.

В текстах употребляются также словообразовательные варианты обеих упомянутых единиц, включающие усеченные основы одного из мотивирующих слов, т.е. справороссы, а также ЕдиРоссы и единороссы. Следует отметить, что название ЕдиРоссы встречается прежде всего в текстах, напечатанных еще до создания партии „Единая Россия”, например, с объяснением, что так в думских кругах называют представителей 4 фракций: „Единство”, „Народный депутат”, „Российские регионы”, „Отечество - вся Россия". В текстах, опубликованных позднее, стабилизировалось и явно преобладает название единороссы.

Как отмечает С. Грабяс 8 , лексические средства, в большей степени, чем другие элементы языковой системы, социально и ситуативно обусловлены. Восприятие наименований членов данной партии тесно связано с отношением получателя сообщения к ней самой. В результате одно и то же название может считаться нейтральным или экспрессивным, например, одобрительным или неодобрительным. Оценочная коннотация появляется как бы на другом уровне, т.е. в словообразовательной основе. Особенно это заметно в номинациях, образованных от фамилий лидеров.

7 В.В. Х и м и к, Большой словарь русской разговорной экспрессивной речи, Санкт-Петербург 2004.

8 S. G r a b i a s, Jezyk w zachowaniach społecznych, Lublin 2001, c. 293. 
Следует подчеркнуть, что указанные в статье наименования часто в контекстах получают экспрессивно-эмоциональную или оценочную коннотацию. Как было упомянуто выше, это связано с отношением автора исходного текста к данной политической партии. Бывает так, что даже в текстах, которые должны быть информационными по своему характеру, читатель сразу чувствует отношение автора к описываемым лицам.

При введении официальных и неофициальных названий членов русских политических партий в польские публицистические тексты обнаруживаются некоторые трудности, связанные со спецификой анализируемой группы слов и с фактом, что при передаче следует учитывать их семантику, словообразовательную структуру в исходном языке, а также коннотации, вызываемые этими культурно обусловленными единицами.

Проблема включения в текст чужих для данного языка элементов остается актуальной. В прессе любой страны практически ежедневно встречаются описания политических, экономических, социальных и культурных событий, происходящих в других государствах. Следовательно, для достижения межкультурного понимания в такого типа текстах авторы используют приемы, предлагаемые теоретиками перевода.

С точки зрения теории перевода такие единицы принадлежат к т.н. безэквивалентной лексике, которая определяется Л.С. Бархударовым как элементы без полных и частичных эквивалентов среди лексических единиц другого языка9. Согласно классификации В.С. Виноградова названия членов политических партий относятся к лексике, содержащей фоновую информацию, точнее говоря - к реалиям государственно-административного устройства и общественной жизни ${ }^{10}$. Все такого типа соответствия являются в польском тексте т.н. потенциальными носителями чуждости ${ }^{11}$, активизирующимися в процессе предполагаемого или фактического восприятия рассматриваемых лексических единиц.

Если автору публицистического текста известны закрепленные в польском языке соответствия наименований русских политических партий ${ }^{12}$, при включении в текст нейтральных официальных анали-

9 Л.С. Б а р х у д а р о в, Язык и перевод, Москва 1975, с. 94.

10 В.С. В и н о г р а д о в, Введение 6 переводоведение, Москва 2001, с. 108.

${ }^{11}$ R. L e w i c k i, Obcość w odbiorze przektadu, Lublin 2000, c. 45.

12 Вопросу перевода названий политических партий посвящена статья автора Названия политических партий в польско-русском и русско-польском переводе, „Przegląd Rusycystyczny" 2008, nr 3(123), c. 115-124. 
тических формаций член (партии) + наименование партии не возникают проблемы, т.е. получается соответствие: członek (partii) + nazwa partii.

Намного сложнее представляется ситуация с введением в польский текст неофициальных наименований членов партий. Попытаемся обсудить решение некоторых переводческих проблем, с ними связанных. Такие поиски иноязычных эквивалентов ведутся на разном уровне. Вопервых, это предложения теоретиков перевода, во-вторых, конкретные приемы журналистов, которые предлагают свои решения. Ниже иллюстрируются конкретные текстовые переводы. Материал для анализа отобран из интернет-изданий польской прессы и порталов, специализирующихся на описании общественно-политической жизни России.

В польских текстах, относящихся к политическим событиям, деятельности политических партий и их представителей, практически не встречаются вполне удовлетворяющие соответствия таких единиц, как: ЛДПР-овиы, СПСовиы, эСэРовиы, эСэРы, единороссы, справедливороссы, элдэnээровиы, яблочники и т.п. Все они передаются в польском языке с помощью выражения członkowie (+ partii) + nazwa partii, ср.:

Najgłośniej przeciwko wieżowcowi protestują cztonkowie liberalnej partii Jabłoko; Jeśliby członkowie LDPR zagłosowali choćby 50/50, spokojnie starczyłoby głosów, by odsunąć prezydenta od władzy.

Приведенные соответствия, хотя и несомненно обеспечивают денотативный уровень эквивалентности, являющийся в этом случае доминирующим, не обеспечивают коннотативного уровня ${ }^{13}$. В результате такого типа лексика по-другому воспринимается носителями языка и читателями, говорящими на других языках, так как она тесно связана с актуальной жизнью народа. Следовательно, анализируемые названия можно причислить к культурно-коннотированной лексике (в широком смысле этого понятия). Поскольку польские тексты, в которых выступают названия членов русских политических партий, являются прежде всего информационными, в какой-то степени можно считать оправданным употребление соответствий, обеспечивающих значение исходных единиц только на денотативном уровне.

Важно подчеркнуть, что в таких случаях возможно, конечно, создание другого, например, транскрибированного эквивалента, отражающего в какой-то степени культурный колорит исходной единицы.

13 Коннотация понимается здесь в широком смысле как любой компонент, который дополняет предметно-понятийное (или денотативное), а также грамматическое содержание языковой единицы и придает ей экспрессивную функцию на основе сведений, соотносимых с эмпирическим, культурно-историческим и мировоззренческим знанием говорящих на данном языке. Ср.: Больщой энцииклопедический словарь. Языкознание, под ред. В.Н. Ярцевой, Москва 1998, с. 236. 
Одновременно надо учесть и то, что поскольку польский читатель недостаточно ориентирован в политической жизни России, такая стратегия могла бы привести к противоположному переводческому эффекту, т.е. к полному непониманию семантики слова и отсутствию каких бы то ни было ассоциаций. Как известно, транскрибированная запись - это один из методов, которые предлагаются теоретиками и практиками перевода при передаче реалий. Однако транскрибированные соответствия разговорных наименований членов партий вообще не появляются в польской прессе, хотя создание их потенциально возможно. Такого типа переводческое решение в этих конкретных случаях привело бы к слишком большому восприятию чуждости и чрезмерной экзотизации перевода, а также к излишнему обращению внимания получателя информации на данную переводческую единицу.

Надо отметить, что окказионально встречаются единичные попытки создания эквивалентов с опорой на одну часть составного наименования партии. В анализируемом материале обнаружилась единица sprawiedliwi как название членов партии Справедливая Россия. Ее, однако, вряд ли можно считать удачной, потому что у польских читателей значение данного слова не ассоциируется с названием партии в России, что осознавалось даже автором примера, о чем свидетельствуют кавычки, ср.: „Żyrinowcy, komuniści i «sprawiedliwi» mają tym razem powody do oburzenia".

Довольно несложно представляется ситуация с наименованиями, образованными от фамилии лидера партии. Так, соответствием русского слова жириновиы является в польских текстах наименование $\dot{z} y$ rinowcy. Деятельность Жириновского настолько яркая и выделяющаяся по сравнению с другими лидерами партий, что является известной читателям польских публикаций. Поэтому мотивировка названия члена связанной с данным лицом партии остается такой же в польском языке. Сама единица żyrinowcy вызывает такой же коммуникативный эффект в переводящем языке, как в исходном языке, и тем самым обеспечивает значение и на денотативном, и на коннотативном уровнях.

Рассматривая польское соответствие слова ^имоновцы, т.е. limonow$c y$, следует отметить неполное отражение культурной коннотации в переводящем языке, ср.: „Posiedzenie niespodziewanie zakłóciła akcja kilku członków Partii Narodowo-Bolszewickiej Eduarda Limonowa, tzw. limonowców". По нашему мнению, в русском языке название членов этой экстремистской, националистической партии вызывает более отрицательные ассоциации, чем в польском языке, потому что фамилия лидера упоминается в польской прессе крайне редко.

Названия членов политических партий, указывающие на определенный идеологический характер той или иной организации, такие 
как коммунисты, либералы, ^иберал-демократы, передаются в польских текстах прямыми лексическими эквивалентами. Это связано с тем, что, как упоминалось выше, они функционируют также в значении 'сторонник, последователь данного идеологического направления', ср.: „Drugi w sondażu lider komunistów Giennadij Ziuganow mógłby liczyć zaledwie na 9\% głosów [...]". Для того чтобы подчеркнуть связь перечисленных названий членов партий с определенной страной, иногда в польских текстах появляется как переводческая оговорка прилагательное rosyjski, cp.: „Kojarzeni z anarchią czasów Jelcyna tzw. rosyjscy demokraci i liberałowie Grigorij Jawliński, Jegor Gajdar, Borys Niemcow zostali odcięci od pieniędzy i znaleźli się na marginesie." Такой прием относится к одному из видов трансформационного перевода ${ }^{14}$.

Как видно на основании собранного материала, названия членов русских политических партий интересны как со словообразовательной точки зрения, так и с точки зрения их перевода. Стоит подчеркнуть, что ассоциации, возникающие при их образовании и употреблении, отражаются и в других словах, связанных с названиями политических партий, например, в прилагательных типа единоросский, яблочный, которые могут вызывать немалые трудности при переводе. Поэтому если даже анализируемые в статье названия членов партий не вошли еще в языковой узус, то, тем не менее, они должны оказаться в сфере заинтересованности лингвистов и переводчиков.

14 Л.С. Б а р х у д а р о в, указ. соч., с. 96. 